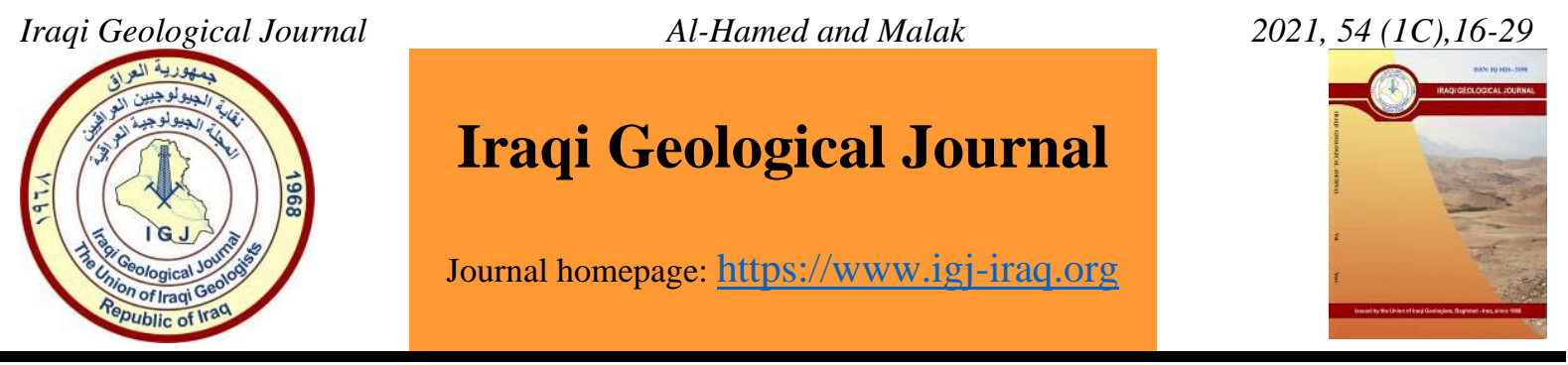

\title{
Comparison Between the Classical Classification and Digital Classification for Selected Samples of Igneous and Carbonate Rocks
}

\author{
Shareef T. Al-Hamed ${ }^{1}$ and Zaid A. Malak ${ }^{1, *}$ \\ ${ }^{1}$ Department of Geology, College of Science, University of Mosul, Iraq \\ * Correspondence: zaidmalak@unmosul.edu.iq
}

Received: 21 September 2020; Accepted: 1 January 2021; Published : 31 March 2021

\begin{abstract}
As igneous rocks have widely chemical and mineralogical compositions, there are many ways to classify these rocks. These ways are classical approved methods to give a reliable classification and nomenclature of rocks. Some igneous rocks may be classified by digital image processing to assist in classical methods. Five igneous samples were cut, prepared of thin sections, and polished to classify them by classical methods and digital image processing by ENVI software. Moreover, part of these samples crushed an analysis of major oxides. The current igneous samples have referred to the basic and mesocratic rocks based on the classical methods and this has corresponded to ENVI software. The igneous samples have reflected the leucogabbros when classify them by classical and ENVI classifications, except the G5 sample, which has been referred to as gabbro by ENVI. There is a clear similarity between the classical and ENVI classifications. ENVI classification is a reliable classification to assist the classical methods in the nomenclature of igneous rocks, especially, plutonic rocks, it can be also applied to thin sections of volcanic rocks to classify and nomenclature classification by ENVI has been applied on fifty thin sections of limestones to identify microfacies which are classified beforehand by classical (optical) classification. According to optical classification, microfacies have classified as mudstone, wackestone, packstone, and grainstone. When the digital classification is applied to them, there is no grainstone texture found in these them. Digital thin sections, where the true name of these microfacies is packstone. Therefore, the positive sides of the digital image processing by ENVI software appeared and contrasted to the optical classification which contained some mistakes when applied to the nomenclature of these microfacies.
\end{abstract}

Keywords: Carbonate rocks; Classification; Digital iimage processing; Igneous rocks

\section{Introduction}

As the igneous rocks have widely chemical and mineralogical compositions Le Maitre et al (1989); Le Bas and Streckeisen (1991) tried to classify these rocks in various ways and used many complex techniques such as petrographic study, XRF, XRD, ICP-MS, EMPA, etc. and employed IUGS the systematics of igneous rocks to give a reliable classification and nomenclature of these rocks. These methods are classical approved methods, but they need a long time to obtain reliable results. Al-Hamed et al (2019) classified pegmatites into syenitic- and gabbroic-pegmatites by digital image processing (ENVI software), where this technique was reliable for coarse-grained rocks. On the other hand, we will address the subject of the beginnings of the classification of limestone rocks. The successful classification of carbonate rocks (limestone) requires awareness of the components and diagenetic processes that intervene on the rocks. Many modern classifications were used optical properties and

DOI: $10.46717 /$ igj.54.1C.2Ms-2021-03-22 
petrographic studies to classify the carbonate rocks. These properties were accredited on the depositional fabric of the rocks, like relative abundantly of the coarse carbonate grains both skeletal and nonskeletal (allochems) comparative with the fine grains (Matrix), type, and size of the grains, etc. To determine the depositional environments of carbonates rocks must be classified texturally, here the hang lenses or thin sections can be used to establish the texture of the rocks. Many classifications were used, some of them developed, such as Folk (1959; 1962), Dunham (1962), Leighton and Pendexter (1962), and Bissell and Chilingar (1967). This paper focuses on the classification of plutonic igneous and carbonate (limestone)rock samples by classical methods and digital classification by ENVI software as a reliable classification to assist in classical classification in the nomenclature of rocks. Where these samples will be classified by classical methods, and then classified by ENVI software to ensure the adoption of digital image processing in the classification of some rocks, especially coarse-grained.

\section{Materials and Methods}

Five igneous samples were taken to the laboratory of the Department of Geology, University of Mosul, Iraq, where they were cut, prepared of thin sections, and polished before point counting and staining processes. Part of these samples was crushed for the analysis of major oxides by Perkin Elmer Sciex-Elan 6000 (ICP-MS) with 4-acids digestion at ACME Analytical Laboratories in Canada (Table 1). The size of polished samples is a personal preference, the only restriction being the ability to fit it within the containers being used for staining. The surface of the hand specimen to be stained needs to be polished only enough to remove any grooves made by the saw blade, where 220 grit is used on a rotary lap wheel to do this. After this, the slab washes off thoroughly in tap water, no cleaner it, allow it to dry, and preparation a laboratory site where the staining can take place where can mix the staining solutions, knowing that the thin sections were prepared before these steps. The staining process involves three chemicals solutions (Bailey and Stevens, 1960; Laniz et al., 1964). First, Hydrofluoric acid (HF) is used to etch the polished surface with a concentration of 46-52\%. Second, Amaranth $\left(\mathrm{C}_{20} \mathrm{H}_{11} \mathrm{~N}_{2} \mathrm{Na}_{3} \mathrm{O}_{10} \mathrm{~S}_{3}\right)$ is used to stain the plagioclase with red color on the polished surface; it mixes about 33 grams of it per $500 \mathrm{ml}$ of distilled water. Third, Sodium Cobaltinitrite $\left(\mathrm{Na}_{3} \mathrm{Co}\left(\mathrm{NO}_{2}\right)_{6}\right)$ is used to stain any alkali-feldspar with yellow color on that surface; it mixes about 20 grams of it per $100 \mathrm{ml}$ of distilled water. It is recommended that the staining is accomplished beneath a well-ventilated hood because the acids are caustic.

Table 1. Major oxides chemical analysis for igneous samples

\begin{tabular}{cccccc}
\hline Sample & G1 & G2 & G3 & G4 & G5 \\
\hline $\mathrm{SiO}_{2}$ & 50.21 & 49.88 & 49.95 & 47.64 & 49.32 \\
$\mathrm{Al}_{2} \mathrm{O}_{3}$ & 13.14 & 16.97 & 18.01 & 14.43 & 16.91 \\
$\mathrm{FeO}$ & 5.39 & 3.89 & 4.96 & 4.99 & 5.98 \\
$\mathrm{Fe}_{2} \mathrm{O}_{3}$ & 2.11 & 4.13 & 3.02 & 4.37 & 3.09 \\
$\mathrm{MgO}$ & 8.02 & 5.15 & 4.93 & 5.01 & 6.22 \\
$\mathrm{CaO}$ & 14.24 & 11.76 & 11.04 & 16.56 & 12.25 \\
$\mathrm{Na} 2$ & 2.95 & 3.58 & 3.75 & 2.21 & 2.82 \\
$\mathrm{~K}_{2} \mathrm{O}$ & 0.68 & 0.62 & 0.66 & 0.55 & 0.49 \\
$\mathrm{P}_{2} \mathrm{O}_{5}$ & 0.22 & 0.12 & 0.2 & 0.92 & 0.13 \\
$\mathrm{TiO}_{2}$ & 1.41 & 1.86 & 1.68 & 1.36 & 1.57 \\
$\mathrm{MnO}$ & 0.23 & 0.14 & 0.20 & 0.16 & 0.12 \\
$\mathrm{LOI}$ & 1.4 & 1.9 & 1.6 & 1.8 & 1.1 \\
& 100 & 100 & 100 & 100 & 100 \\
\hline
\end{tabular}


The staining process was described by Bailey and Stevens (1960), and by Laniz et al (1964). With certain modifications to their work, the staining is accomplished by following these steps:

1. In a well-ventilated hood, pour the Hydrofluoric acid into a vessel to about $1 / 4$ inch of the top.

2. Dip the polished surface into the Hydrofluoric acid for approximately two minutes.

3. Dip the polished surface in the distilled water for 10 seconds by moving the polished face under the surface of water or gently dipping the slab in the water and out of from the water several times to approximately 10 seconds.

4. Dip the same surface into the Amaranth solution for approximately $2-5$ seconds.

5. Dip the polished surface in the second vessel of distilled water to 10 seconds for rinse off the Amaranth as in step 2 above.

6. Catch the slab in a tilted position to it is dry from excess Amaranth by using a blow dryer, but be very careful not to blow off any of the red-colored stains which have formed on the plagioclase.

7. Dip the same surface of the slab into the solution of Sodium Cobaltinitrite for approximately 1.5 minutes.

8. Dip this surface in the third vessel of distilled water for 10 seconds as in step 2 above.

9. Dry off the slab as in step 5, the K-feldspar should be obtained stained a yellow color.

10. Last but not least, place the stained slabs, face-up, on paper towels and let dry under a heat lamp for several minutes or leave to dry overnight. The staining is complete now. Accordingly, the plagioclase is stained red by using of Amaranth and the red tone increases with increase the calcium in the plagioclase, ferromagnesian minerals such as pyroxenes will have a black colour, and $\mathrm{K}$-feldspar minerals are stained in yellow colour by using of Sodium Cobaltinitrite. The images concerning the polished rock slabs and the stained surfaces, as captured by a digital camera, have to be transformed into a different image mode using the ENVI software. An image processing analysis has been undertaken for the mineral proportions to be automatically evaluated and the appropriate nomenclature to be retrieved. Thus, the digital image processing is applied on polished slabs for the purpose to calculate and recalculate the colour index $\mathrm{M}^{\prime}$, quartz, alkali-feldspar, and plagioclase proportions to be suitably plotted in classical classification diagrams. The classifications of carbonate rocks depend on the ratios of the components usually can be calculated visually and estimating the proportions of them by the petrographic study. These classifications tended to be rather arbitrary and they frequently overlap or do not fit one's particular needs. Since this process is done manually, the individual observations may vary; this could possibly lead to misclassification by the observer. When binocular microscopes or hand lenses are used it is usually possible to identify the individual grains forming the rock, two classifications that are widely used are Folk (1959; 1962) (Fig. 1) and Dunham (1962) (Fig. 2). Sometimes, these classifications are accompanied by errors in estimating the proportions of the components and this is reflected negatively on naming the facies and it occurs mistakes in determining the sedimentary environment of any formation. Therefore, it is necessary to find a more consistent, accurate, and rapid method to classify the carbonate rocks into the correct group, where the digital image processing technique is a simple and modern method to classify limestone. Limestones are cut to prepare the thin sections and classification them by digital image processing. This will be achieved by determining the black and white pixels of the binary images, which represent the allochems and matrix of the microfacies. Digital image processing used to diminish the mistake which is resultant of inaccurate component ratio under the microscope which is the basis on the nomenclature of the facies, this technique requires several steps:

The first step (Image acquirement): After doing rocks thin sections, taking image process to begin for carbonate rock texture under the microscope, thereby the slide transference to image with two dimensions as a digital format, then this image locomotion as digital data to the computer to applicable dealing with image classification by ENVI software.

The second step (image coloring): Hereafter upload the image to the computer; the database of all images must be available by coloring the image through a two-color alien for each other. The 
groundmass (matrix) is colored by black while the components of the grains are coloured by another colour (white).

The third step (account percentage): The program will deal with two colours of the whole image area as 100/100. After translating the original image from the white (grains) and milky colours (Matrix) to the white and black colour respectively, the program begins to calculate the ratio of the white area (grains components) requited to $100 \%$, as well as, the ratio of the black area (Matrix) requited to $100 \%$. The ratio of grains which are coloured by white very significant, the outcome of the image contains a high percentage of grains such as (grainstone) have wide white space because the ratio of grains which are composed of fossils, pelloid, oolits, and intraclasts are dominant. Opposite that the facies which contain a small amount of grains components which the ratio of lime mud dominant such as (mudstone) facies, where the ratio of the black area very small because of the low amount of grains less than $10 \%$ compared with the fine homogenous matrix. Through the calculation, the ratio between the white and black areas of the whole image shows several reliable and truly results in the classification of carbonate rocks (limestone) more than the result which depends on the optical senses.

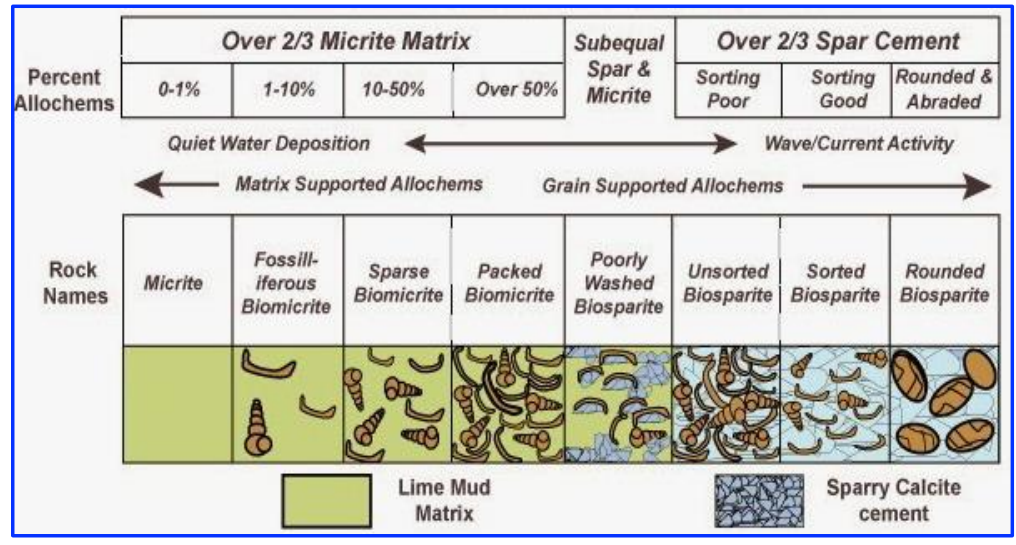

Fig. 1. Classification of carbonate rocks (Folk, 1959)

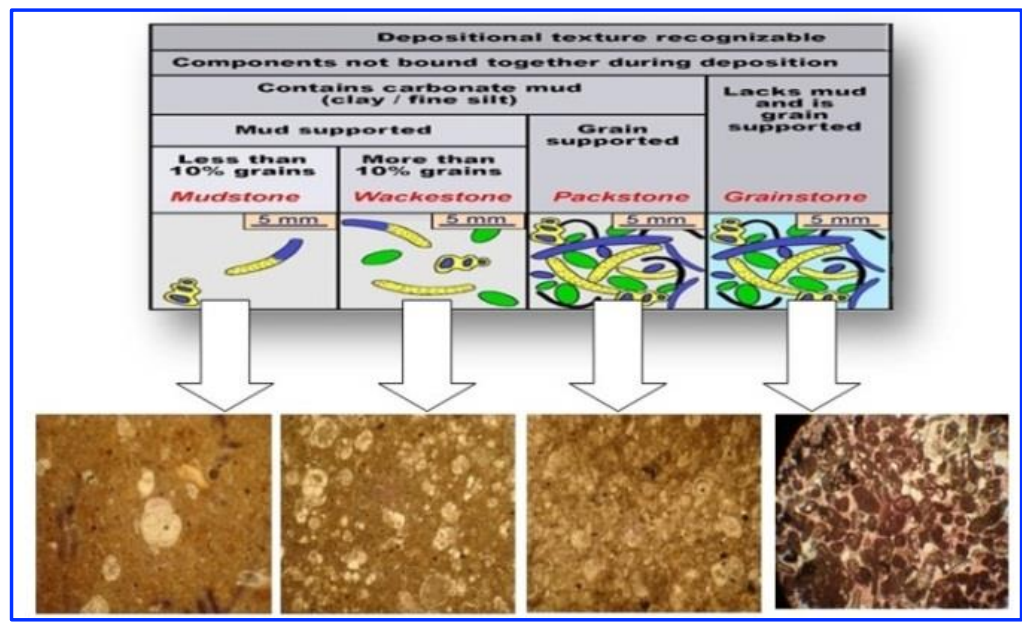

Fig. 2. Classification of carbonate rocks (Dunham, 1962)

\section{Results and Discussion}

\subsection{Igneous Samples}

The silica content in these samples is from $46.64 \mathrm{wt}$. \% to $50.21 \mathrm{wt}$ \% (Table 1), indicating the basic type of rocks (Fig. 3). In igneous rock, hololeucocratic, leucocratic, mesocratic, melanocratic, and ultramafic terms (Fig. 4) refer to the relative proportions of dark and light minerals, the percentage of 
dark minerals is known as the color index $(\mathrm{M})$ which is mafic and related minerals (accessory minerals) (Streckeisen, 1976). The absolute values of $\mathrm{M}$ are 0-10\% in hololeucocratic, 10-35\% in leucocratic, $35-65 \%$ in mesocratic, 65-90 \% in melanocratic, and 90-100\% in ultramafic (Gillespie and Styles, 1999). Quantitative measurements of mineral proportions in the thin sections that depend on the point counting refer to the colour index $\left(\mathrm{M}^{\prime}\right)$ is between $42.4 \%-49.5 \%$, this reflects the mesocratic rocks (Table 2).

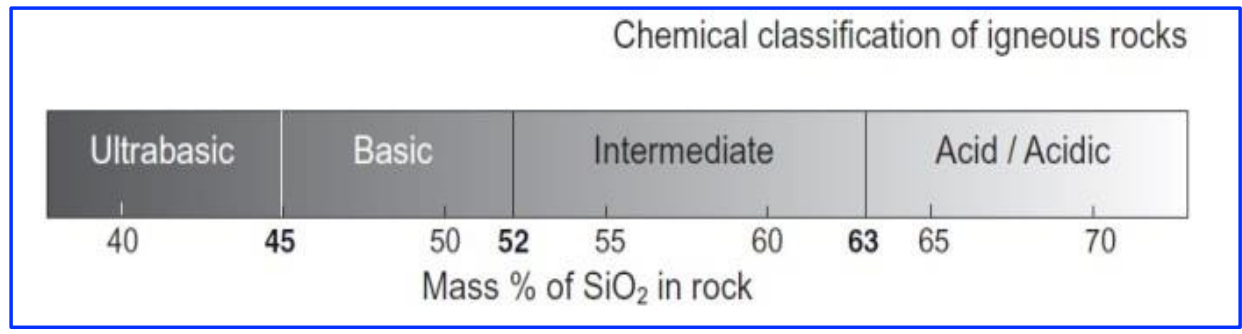

Fig. 3. Silica content, the boundary between intermediate and acidic has been placed at $63 \% \mathrm{SiO}_{2}$ in conformity with (Le Maitre, 2002)

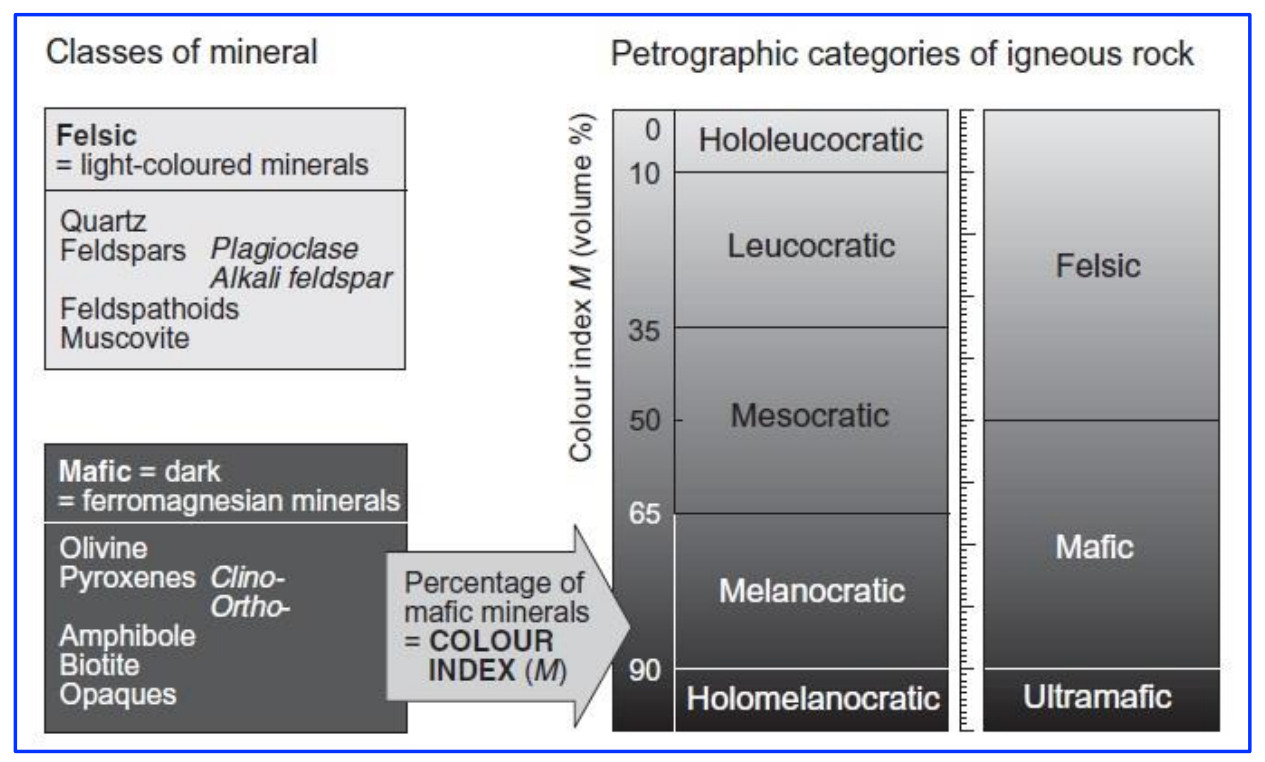

Fig. 4. Volume proportions of light (felsic) and dark (mafic) minerals observed under the microscope (Gill, 2010)

Petrographic study indicates that these rocks are composed of a coarse-grained of labradorite (Table 3) (sometimes, primary labradorite suffers albitization, it alters to secondary albite), augite, hornblende, olivine, and a small amount of K-feldspar (Fig. 5 a, b, c, and d). Moreover, most of the samples show ophitic and sub-ophitic texture (Fig. 5c). Mode analyses were calculated and recalculated by point counting in the thin section (Table 4 and Table 5) to plot these proportions in the ternary diagrams (Pyroxene-Olivine), (Plagioclase-Orthopyroxene-Clinopyroxene), (Plagioclase-PyroxeneHornblende), and (QAP) to classify the igneous samples (Figs. 6 and 7). All of these diagrams refer to that the igneous samples are the gabbroic type. In the QAP diagram, samples have occurred into the gabbroic-dioritic field, the extinction angle of plagioclase was calculated to find out An mol.\% in the plagioclase using the Michale Levy method (1889) to differentiate between gabbro and diorite, where calcic (An > 50) for gabbro and sodic for diorite (Le Maitre, 2002). The plagioclase composition was labradorite in these samples (Table 3), reflecting the gabbroic rocks.

According to classic approved methods are mentioned above, the igneous samples are leucogabbros, where An mol. \% > 50\% (Table 3) and M' < 50\% (Table 2) (Gillespie and Styles, 1999). 
Table 2. Recalculation of the color index (M') by point counting

\begin{tabular}{ccc}
\hline Samples & M & $\mathbf{M}^{\prime}$ \% \\
\hline G1 & 49 & 49.5 \\
G2 & 42 & 42.4 \\
G3 & 44 & 44.9 \\
G4 & 45 & 45.5 \\
G5 & 43 & 43.4 \\
\hline
\end{tabular}

$\mathrm{M}=$ Sum of mafic minerals, where sum of mafic $=$ Clinopyroxene + Orthopyroxene + Olivine + Hornblende + Opaque (Magnetite + Ilmenite), taken from Table 4.

$\mathrm{M}^{\prime} \%=100 \times$ [Sum of mafic/Total of minerals], where total of minerals $=$ Clinopyroxene + Orthopyroxene + Olivine + Hornblende + Opaque + Alkali-feldspar + Plagioclase + Quartz, taken from Table 4.

Table 3. The composition of plagioclase

\begin{tabular}{cccl}
\hline Sample & Extinction angle & An mol. \% & Plagioclase \\
\hline G1 & $29-31$ & $52-56$ & Labradorite \\
G2 & $29-31$ & $52-56$ & Labradorite \\
G3 & $30-33$ & $54-59$ & Labradorite \\
G4 & $29-32$ & $52-57$ & Labradorite \\
G5 & $31-33$ & $56-59$ & Labradorite \\
\hline
\end{tabular}
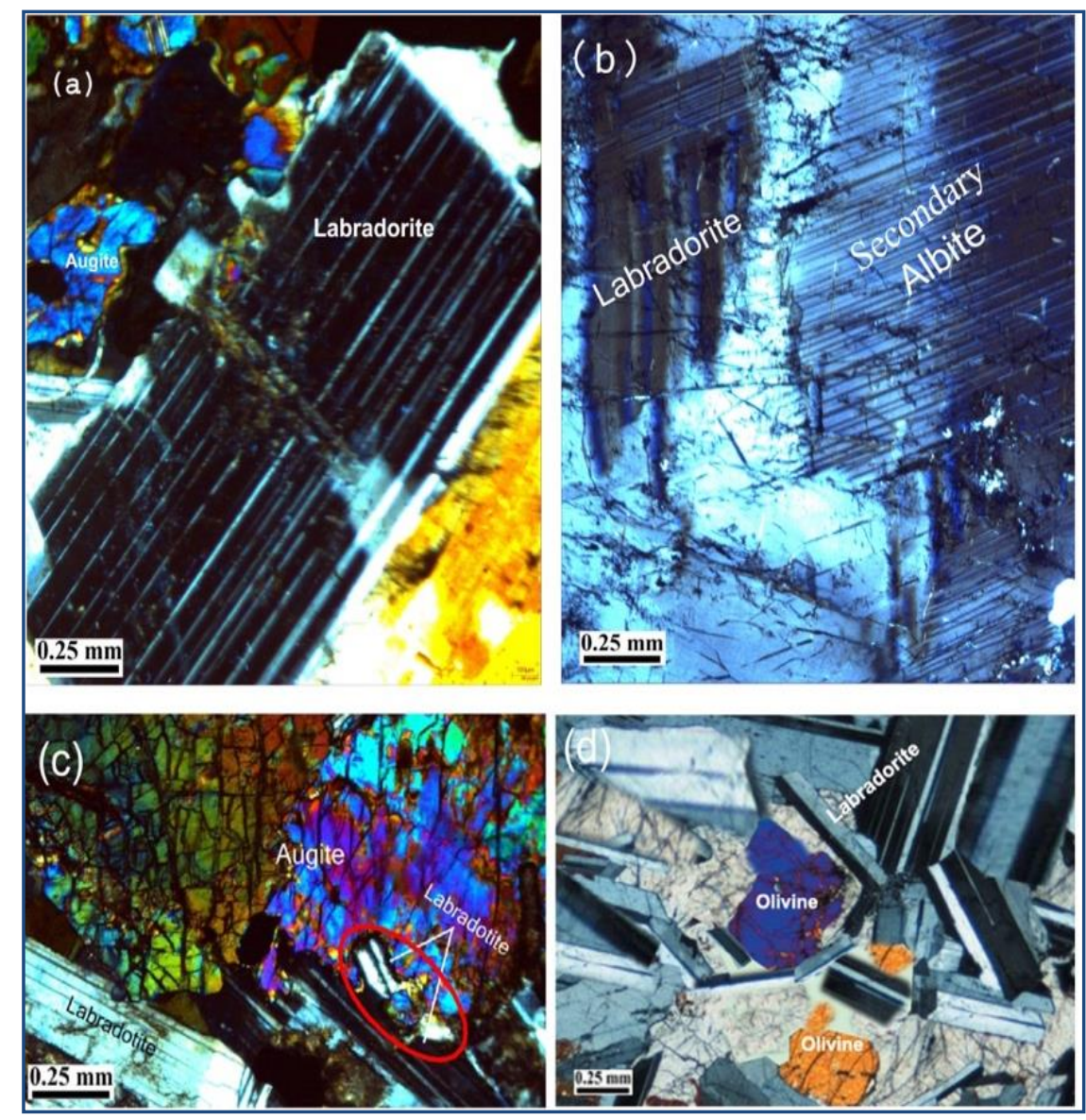

Fig. 5. (a) Euhedral labradorite crystal; (b) Labradorite alteration; (c) Ophitic texture and (d) Olivine-plagioclase accumulation 
Table 4. Calculations of mod analysis by point counting

\begin{tabular}{lccccc}
\hline Sample & G1 & G2 & G3 & G4 & G5 \\
\hline Quartz & 0 & 0 & 0 & 0 & 0 \\
Alkali-feldspar & 4 & 5 & 4 & 4 & 3 \\
Plagioclase & 46 & 52 & 50 & 50 & 53 \\
Clinopyroxene & 33 & 24 & 21 & 30 & 27 \\
Orthopyroxene & 0 & 0 & 0 & 0 & 0 \\
Olivine & 5 & 3 & 6 & 1 & 6 \\
Hornblende & 5 & 7 & 7 & 8 & 7 \\
Opaque & 6 & 8 & 10 & 6 & 3 \\
Total & 99 & 99 & 98 & 99 & 99 \\
\hline
\end{tabular}

Table 5. Recalculation of mod analysis by point counting

\begin{tabular}{|c|c|c|c|c|c|c|c|c|c|c|c|c|}
\hline \multirow[t]{2}{*}{ Sample } & \multicolumn{3}{|c|}{ Plag-Px-OI diagram } & \multicolumn{3}{|c|}{ Plag-Opx-Cpx diagram } & \multicolumn{3}{|c|}{ Plag-Px-Hbl diagram } & \multicolumn{3}{|c|}{ QAP diagram } \\
\hline & Plag & $P x$ & $\mathrm{Ol}$ & Plag & Opx & Cpx & Plag & $P x$ & $\mathrm{Hbl}$ & $\mathrm{Q}$ & A & Plag \\
\hline & & & & & & $\%$ & & & & & & \\
\hline G1 & 54.8 & 39.3 & 5.95 & 58.23 & 0.0 & 41.77 & 54.76 & 39.29 & 5.95 & 0.0 & 8 & 92 \\
\hline G2 & 65.82 & 30.4 & 3.8 & 68.42 & 0.0 & 31.58 & 62.65 & 28.92 & 8.43 & 0.0 & 8.77 & 91.23 \\
\hline G3 & 64.94 & 25.3 & 7.23 & 70.42 & 0.0 & 29.58 & 64.10 & 26.92 & 8.97 & 0.0 & 7.41 & 92.59 \\
\hline G4 & 61.73 & 37.04 & 1.23 & 62.5 & 0.0 & 37.5 & 56.82 & 34.09 & 9.09 & 0.0 & 7.41 & 92.59 \\
\hline G5 & 61.63 & 31.4 & 7 & 66.25 & 0.0 & 33.75 & 60.92 & 31.03 & 8.05 & 0.0 & 5.36 & 94.64 \\
\hline
\end{tabular}

Plag (plagioclase); Px (pyroxene); Ol (olivine); Cpx (clinopyroxene); Opx (orthopyroxene); Hbl (hornblende); Q (quartz) and A (alkali feldspar)

The digital image processing technique by ENVI software has been implemented on the original samples (polished rock slabs) before the staining step to determine the appropriate color index $\left(\mathrm{M}^{\prime}\right)$ (Fig. 8) (Table 6). The images of polished rock slabs will give two colors by ENVI software, the white color of felsic minerals and the black color of mafic minerals (Fig. 8). The color index of these samples is between $44.754 \%-57.266 \%$, indicating the mesocratic rocks. Calculated color index by point counting (Table 2) also refers to the mesocratic rocks; this indicates that the digital image processing by ENVI software is similar to the classical classification by point counting. The digital image processing is applied on stained slabs to calculate and recalculate the proportions of plagioclase, mafic minerals, alkali-feldspar, and quartz to be plotted in the QAP diagram (Table 6). Accordingly, the stained slabs images will give three colors by ENVI software (Fig. 9), red (for plagioclase), black (for pyroxene, hornblende, and olivine), and yellow (for a small amount of K-feldspar), where the quartz proportions are absence in these samples. All igneous samples have been plotted in the gabbroic-dioritic field (Fig. 10). Moreover, an extinction angle has been calculated concerning the plagioclase to differentiate between gabbro and diorite, where the plagioclase composition was labradorite (Table 3), reflecting the gabbroic rocks. The igneous samples that are classified by ENVI software are gabbros, the color index refers to G1, G2, G3, and G4 samples are leucogabbro, because of the An mol. \% is greater than 50\% (Table 3) and M' less than 50\% (Table 6), whereas the G5 sample is gabbro due to the An mol. \% and $\mathrm{M}^{\prime}$ are more than $50 \%$ (Tables 3 and 6).There is a clear similarity between the classical classification and digital image processing by ENVI software, where ENVI classification may give clear results when applied to acidic and intermediate plutonic rocks, but with regard to color index, ENVI software gives impressive results when applied to all plutonic rocks. 


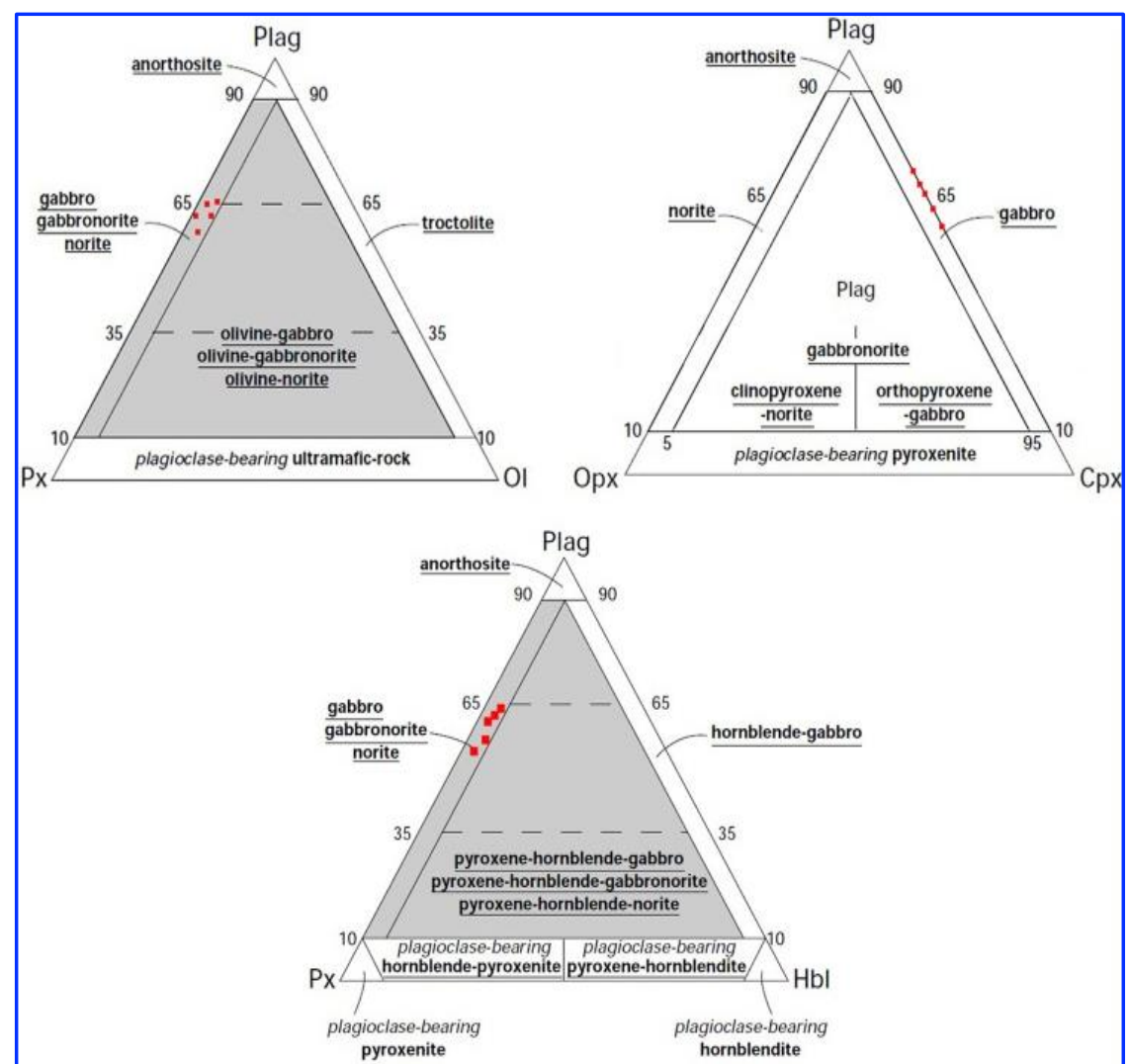

Fig. 6. Classification and nomenclature of gabbroic rocks based on the proportions of Plag, $\mathrm{Px}, \mathrm{Ol}, \mathrm{Cpx}$, and $\mathrm{Hbl}$ (Streckeisen, 1976)

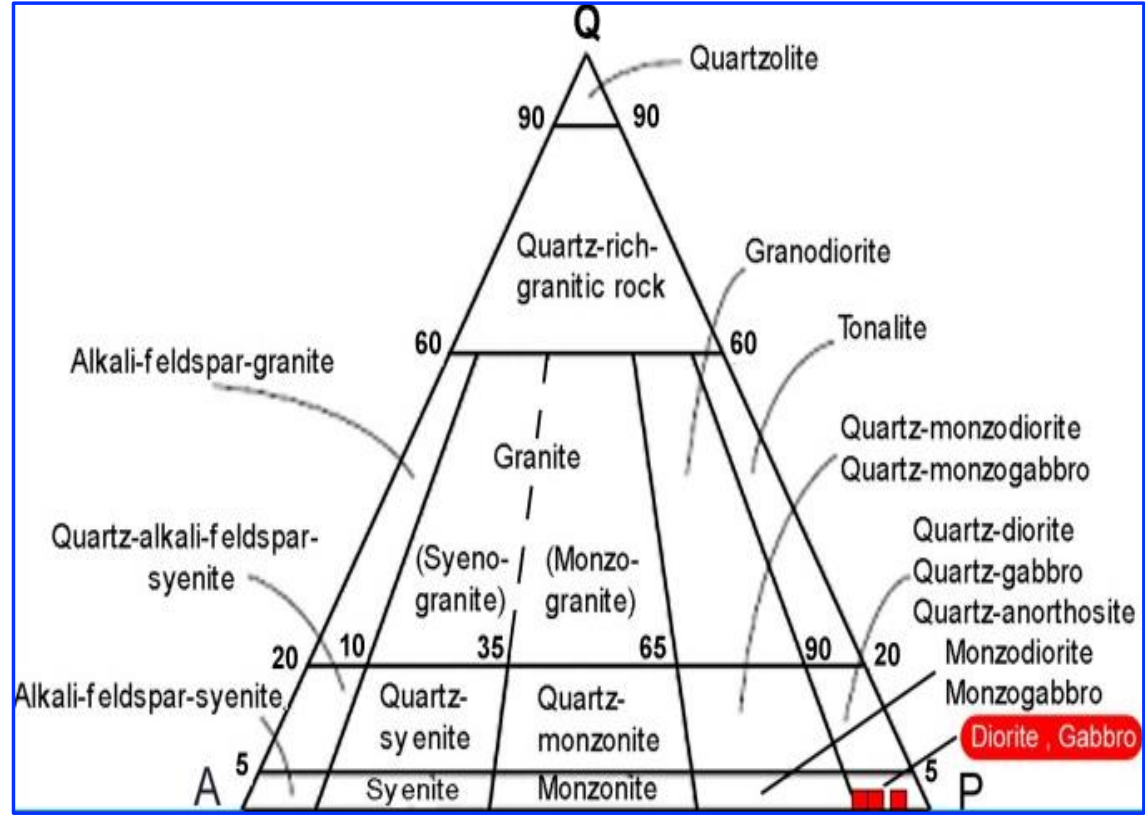

Fig. 7. Classification and nomenclature of the coarse-grained crystalline rocks (Streckeisen 1976) 


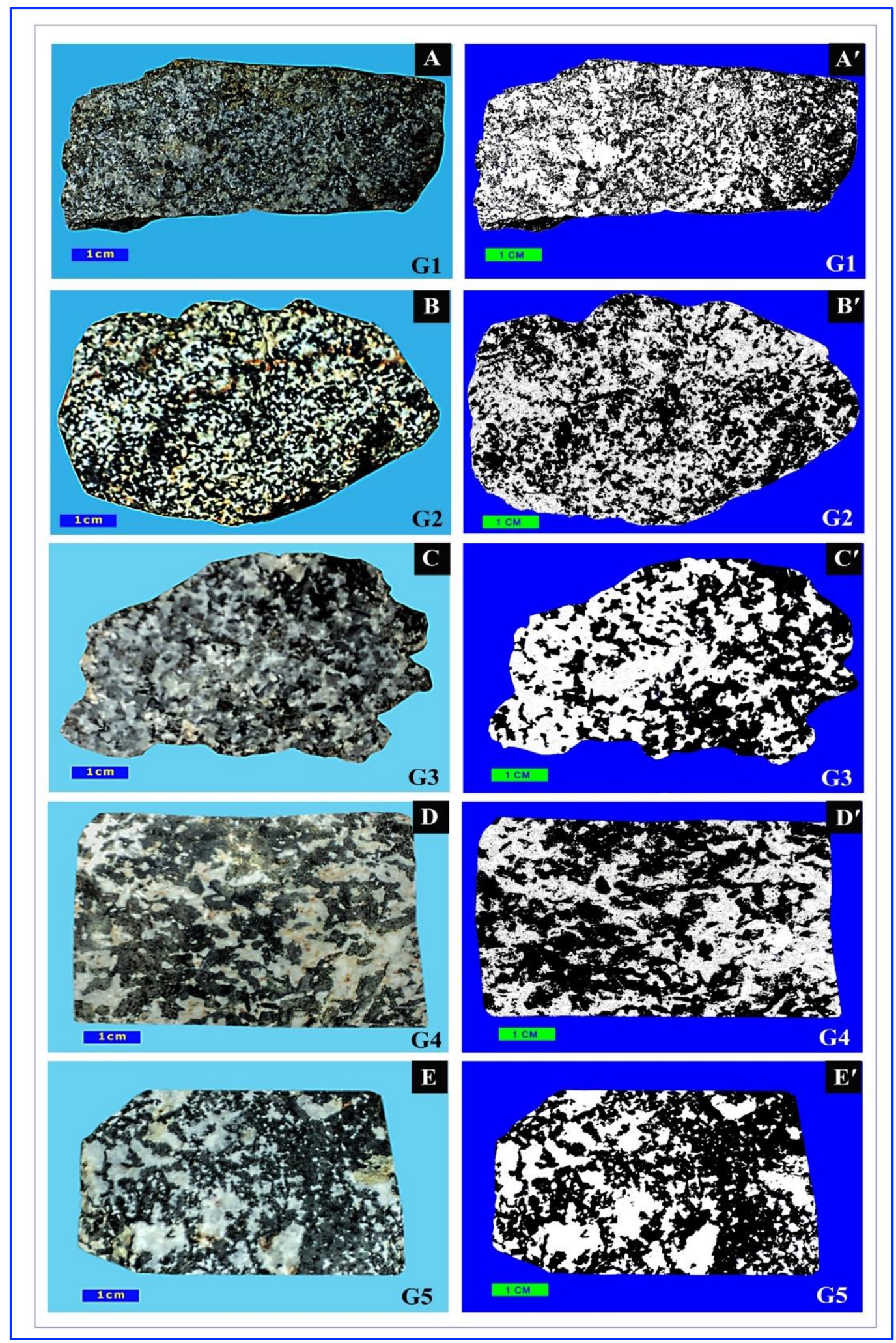

Fig. 8. $A, B, C, D$, and $E$ original samples; $A^{\prime}, B^{\prime}, C^{\prime}, D^{\prime}$, and $E^{\prime}$ the same slabs which applied it the digital image processing to calculate the color index 


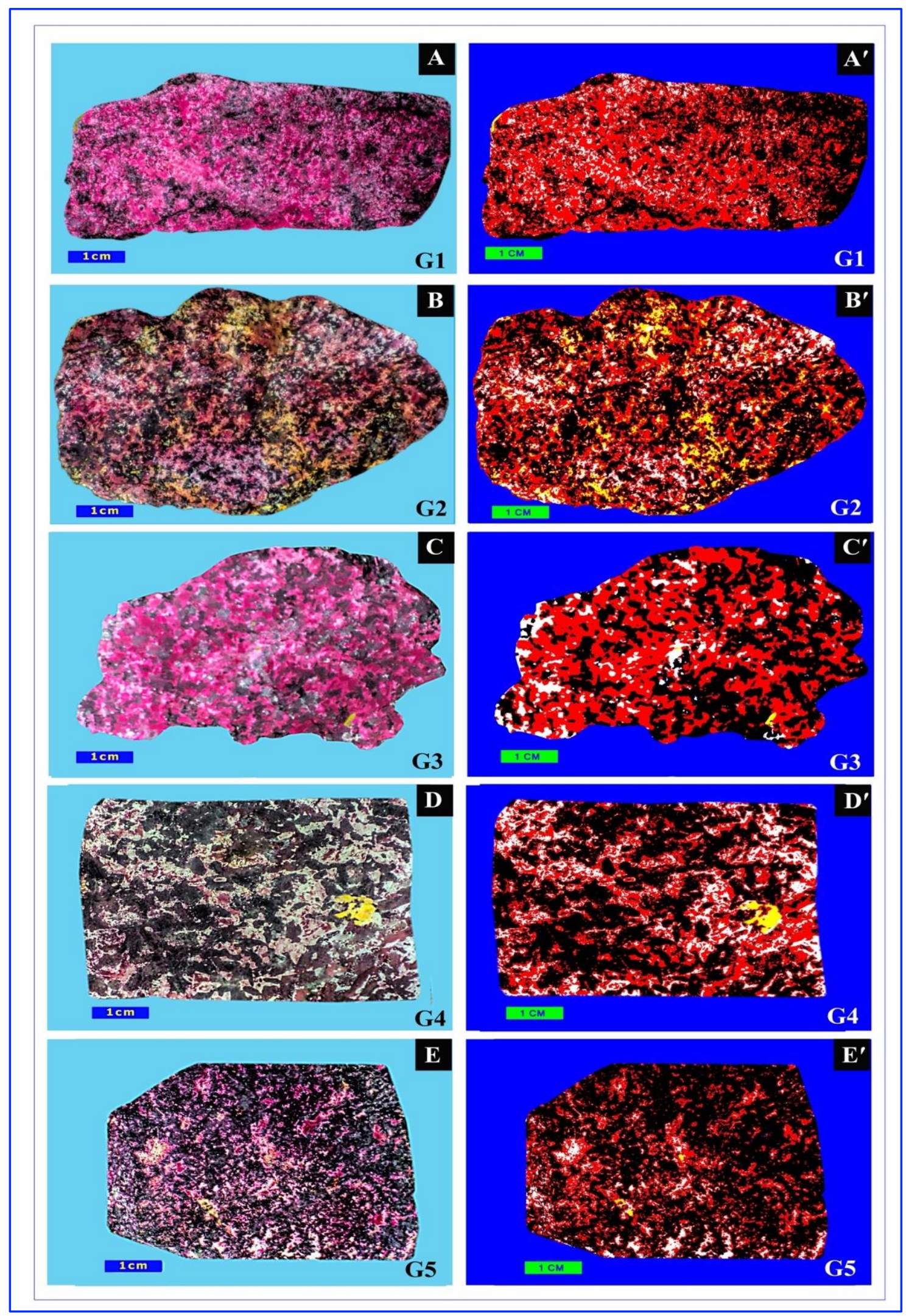

Fig. 9. A, B, C, D, and E the stained slabs; $A^{\prime}, B^{\prime}, C^{\prime}, D^{\prime}$, and $E^{\prime}$ the same slabs which applied the digital image processing to calculate the ratio of alkali-feldspar, plagioclase, and quartz 
Table 6. Calculation and recalculation of the color index $\mathrm{M}^{\prime}$, quartz, alkali-feldspar, and plagioclase proportions for plotting in the ternary diagram (QAP) with classification and nomenclature studied igneous samples

\begin{tabular}{|c|c|c|c|c|c|c|c|c|}
\hline \multirow[t]{2}{*}{ sample } & Quartz & Alkali Feldspar & Plagioclase & $\mathbf{M}^{\prime}$ & \multicolumn{3}{|c|}{ QAP diagram } & \multirow[t]{2}{*}{ Rock name } \\
\hline & & $\%$ & & & $\mathrm{Q}^{\prime} \%$ & $\mathrm{~A}^{\prime} \%$ & $\mathrm{P}^{\prime} \%$ & \\
\hline G1 & 0.000 & 0.088 & 55.158 & 44.754 & 0.000 & 0.159 & 99.841 & Leucogabbro \\
\hline $\mathrm{G} 2$ & 0.000 & 4.957 & 49.484 & 45.559 & 0.000 & 9.104 & 90.896 & Leucogabbro \\
\hline G3 & 0.000 & 0.153 & 54.646 & 45.201 & 0.000 & 0.279 & 99.721 & Leucogabbro \\
\hline G4 & 0.000 & 0.846 & 49.772 & 49.382 & 0.000 & 1.671 & 98.329 & Leucogabbro \\
\hline G5 & 0.000 & 0.141 & 42.593 & 57.266 & 0.000 & 0.330 & 99.670 & Gabbro \\
\hline
\end{tabular}

Alkali Feldspar $=100 \times[\mathrm{A} /(\mathrm{M}+\mathrm{A}+\mathrm{P})]$, Plagioclase $=100 \times[\mathrm{P} /(\mathrm{M}+\mathrm{A}+\mathrm{P})]$, and $\mathrm{M}^{\prime} \%=100 \times[\mathrm{M} /(\mathrm{M}+\mathrm{A}+\mathrm{P})]$. Quartz + Alkali Feldspar + Plagioclase $+\mathrm{M}^{\prime}=100$.

$\mathrm{A}^{\prime} \%=100 \times[\mathrm{A} /(\mathrm{A}+\mathrm{P})]$ and $\mathrm{P}^{\prime} \%=100 \times[\mathrm{P} /(\mathrm{A}+\mathrm{P})] \cdot \mathrm{Q}^{\prime}+\mathrm{A}^{\prime}+\mathrm{P}^{\prime}=100$.

M: Mafic minerals (black color in Fig. 8). P: Plagioclase (primary is red color and secondary is a white color in Fig. 9). A: Alkali-feldspar (yellow color in Fig. 9).

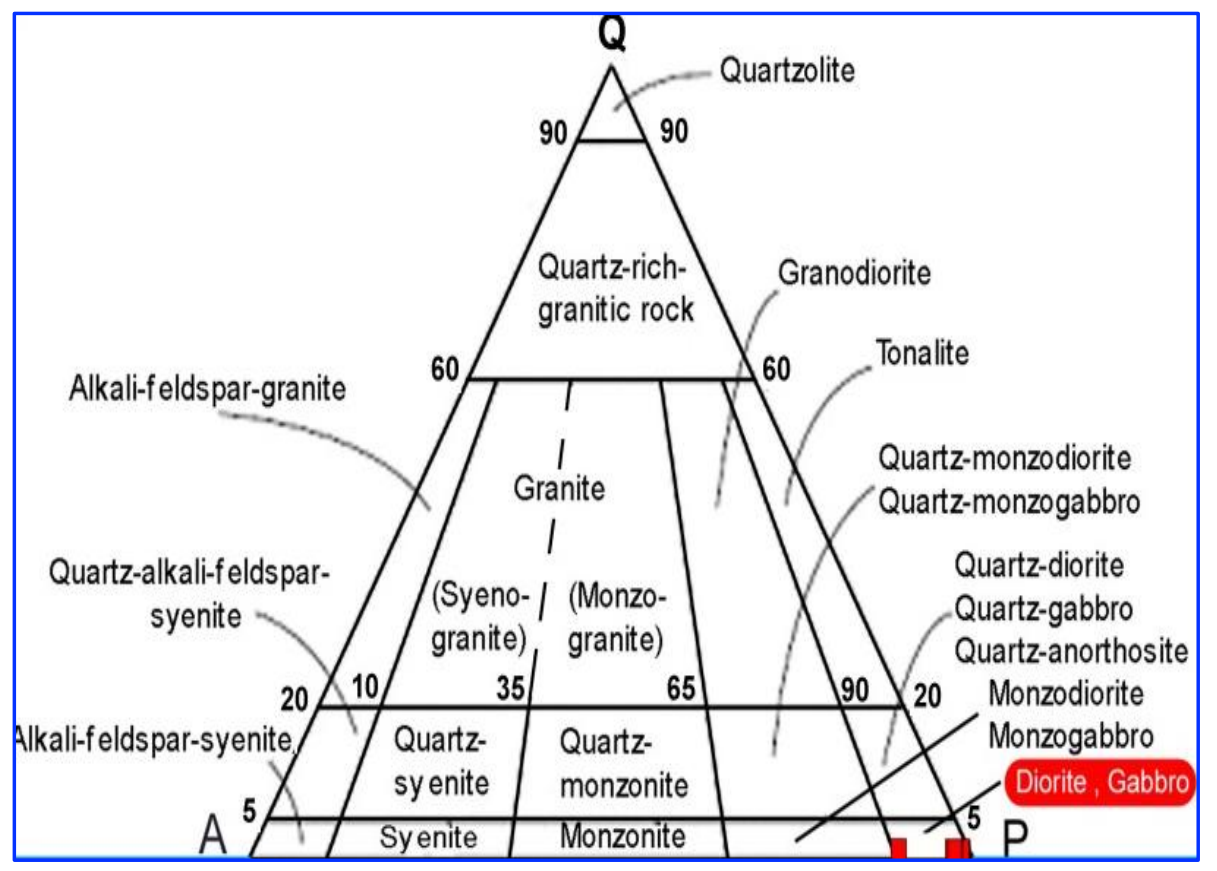

Fig. 10. Classification and nomenclature of coarse-grained crystalline rocks according to their modal mineral contents using the QAP diagram (Streckeisen, 1976)

\subsection{Carbonate Samples}

In the limestone rocks, the digital image processing by ENVI software is used to reclassification the carbonate rocks depending on fifty thin sections classify beforehand by optical classification, the thin sections are viewed under the microscope and taking image process to begin for carbonate rock texture under the microscope. Thereby the thin section transfer from three dimensions to a digital image with two dimensions, this image portage to the computer then database adapt for all image by coloring this image with two different colours. The background (matrix) is coloured by black while the grains (skeletal and non-skeletal components) are coloured by white colour. The image arrangement according to increase the components of grains (white colour) to explain that the white colour increase in the thin section (microfacies) with increasing the ratio of these components. 
From Fig. 11, it can be seen that skeletal components (white colour) have the lowest percentage, which is supposed to be less than $10 \%$, while the matrix (black colour) has the highest ratio, these microfacies named mudstone according to Dunham (1962) classification. The ratio of white color $(6.156 \%)$ locates within the normal range (less than 10\%) of grains of these microfacies. That means the two nomenclatures were true or congruent.
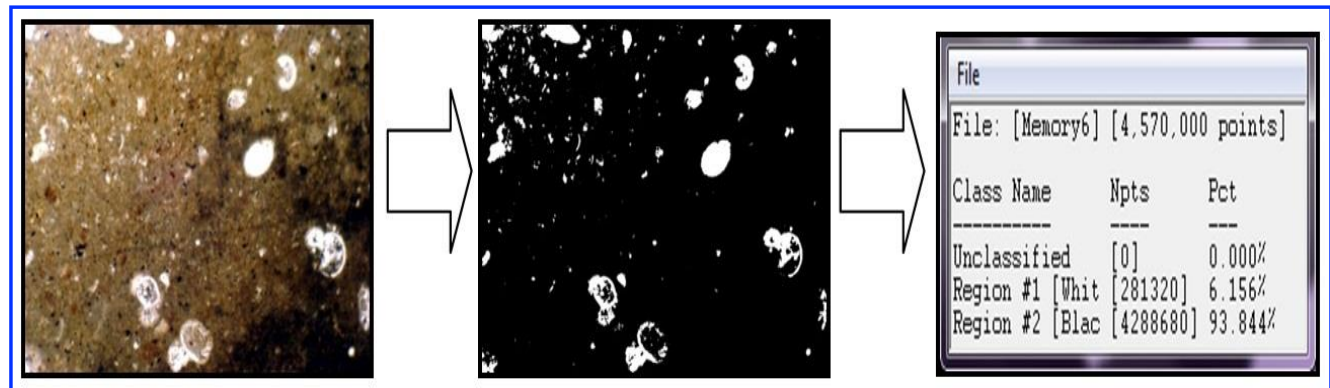

Fig. 11. Thin section image under the microscope (mudstone microfacies), the same thin section processing with white and black color, and calculation the ratio of grains relative to matrix

Furthermore, from Fig. 12, the white colour skeletal components begin with increasing compare with the low ratio of the black colour matrix, the grains are supposed to be less than $50 \%$ to $10 \%$. These microfacies are named wackestone according to Dunham (1962) classification. The ratio of white colour (29.465\%) locates between $10-50 \%$ of the total area of these microfacies. That means the two nomenclatures were congruent.

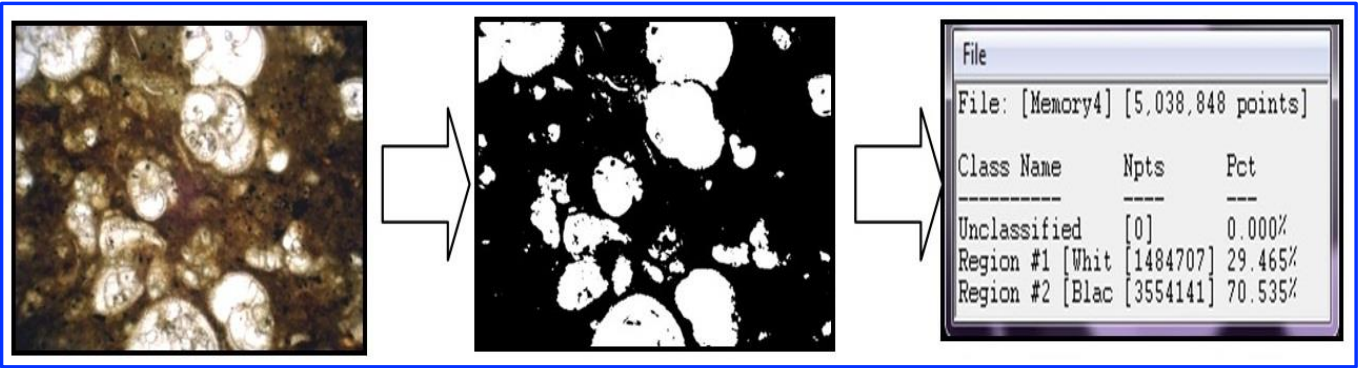

Fig. 12. Thin section image under the microscope (wackestone microfacies), the same thin section processing with white and black color, and calculation the correct ratio of grains relative to matrix

The same speech identical in Fig. 13, but here the white colour skeletal components have a ratio reached to more than $50 \%$ of the all image area compare with the very low ratio of the black colour matrix, here the microfacies named packstone and the two nomenclatures were congruent.

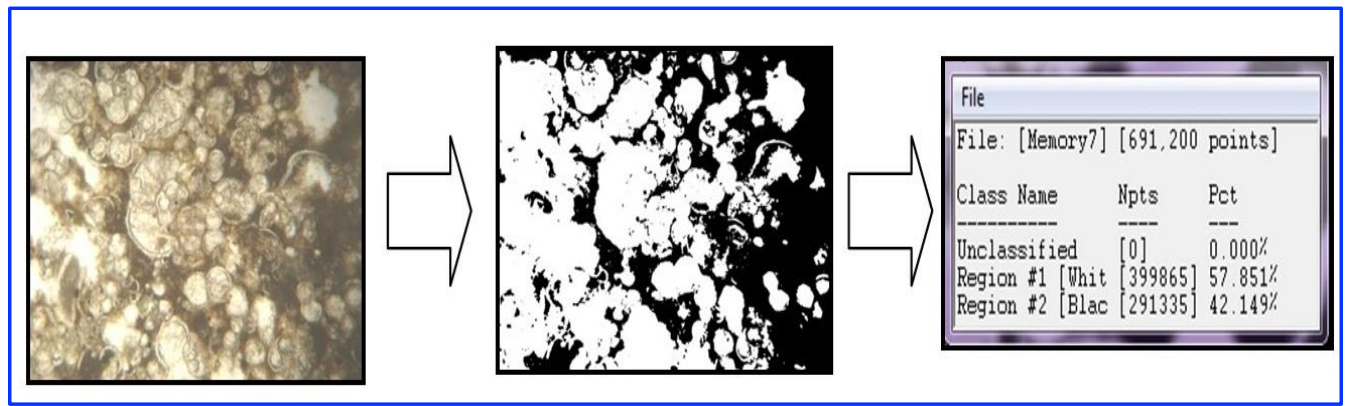

Fig. 13. Thin section image under the microscope (packstone microfacies), the same thin section processing with white and black color to calculate the ratio of grains (white color) relative to the matrix (black color) 
Returning to the previous images of the fifty slides, whose facies were named according to the previous traditional method, we note that there are some errors in naming, especially after these images were subjected to digital image processing for the purpose of reclassifying them. Since we notice that the errors in naming included some of the microfacies that were previously called grainstone, and it was found that the correct and accurate designation for it is packstone. From Fig. 14 according to the classical classification of Dunham (1962), this microfacies is named grainstone, here the white colour skeletal components have a ratio reached to more than $85 \%$ of the all image area compare with the very low ratio of the black colour matrix according to the optical properties. While by using digital Image processing the idea differs, here the white colour skeletal components have a ratio reached to more than $52.9 \%$ of the all image area compare with the low ratio (47.1\%) of the black colour matrix, and the true name of this microfacies is packstone. Here the positive sides of the digital image processing technique appeared and this is contrary to the classical classification which is containing mistakes when used to nomenclature these microfacies.

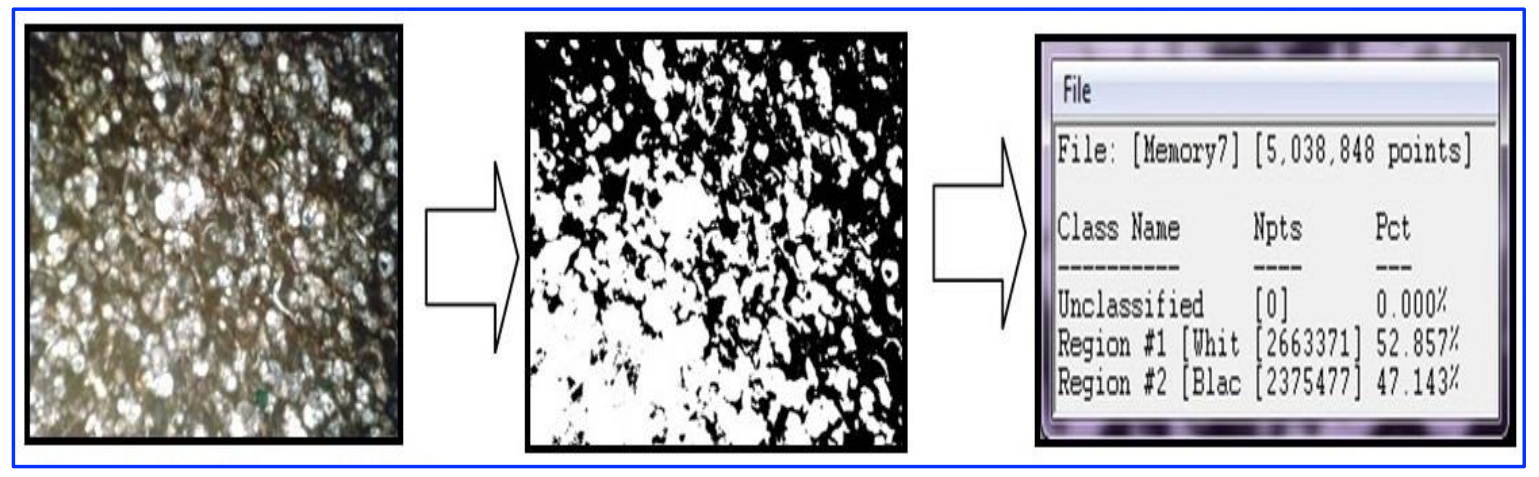

Fig. 14. Thin section image under the microscope (Grainstone microfacies), the same thin section processing with white and black color to calculate the ratio of grains (white color) relative to matrix (black color). The last image shows the mistake which results from incorrect calculation of grains to matrix ratio

\section{Conclusions}

The current igneous samples have referred to the basic and mesocratic rocks based on the classical methods and this has corresponded to digital image processing by ENVI software. According to An mol. $\%$ and $\mathrm{M}^{\prime}$, the igneous samples have reflected the leucogabbros when classify them by classical methods and ENVI software, except G5 sample, has referred to gabbro by ENVI software. There is a clear similarity between the classical classification and digital image processing by ENVI software, where ENVI classification may give clear results when applied to acidic and intermediate plutonic rocks, but concerning color index, ENVI software gives impressive results when applied to all plutonic rocks. The digital image processing by ENVI software is a reliable classification to assist the classical methods in the nomenclature of igneous rocks, especially, plutonic rocks. ENVI classification can also be applied to thin sections of volcanic rocks to classify and nomenclature them.

Limestone rocks have been reclassified by digital image processing (ENVI software) of fifty thin sections and images represent the microfacies which are classified beforehand by classical (optical) classification. According to optical classification, microfacies have classified as mudstone, wackestone, packstone, and grainstone. There is no grainstone texture found in these thin sections when ENVI classification applied to them, here the idea has differed, and the true name of these microfacies was packstone. Therefore, the positive sides of the digital image processing by ENVI software appeared and contrasted to the optical classification which contained some mistakes when applied to the nomenclature of these microfacies. 


\section{Acknowledgements}

The authors are very grateful to the College of Sciences, University of Mosul for their provided facilities, which help to improve the quality of this work. So, we would like to thanks Prof. Dr. Ali Ismail Al-Juboury for his helpful and constructive review, which improved the manuscript. The authors are very grateful to the Editor in Chief Prof. Dr. Salih M. Awadh, the Secretary of Journal Mr. Samir R. Hijab. and the Technical Editors for their great efforts and valuable comments.

\section{References}

Al-Hamed, S.T., Aswad, K. J., Aziz, N. R., 2019. Classification of Composite Pegmatite via Staining and Digital Image Processing in the Bulfat Complex, Qala Deza, NE (Iraq). In: Doronzo D., Schingaro E., ArmstrongAltrin J., Zoheir B. (eds) Petrogenesis and Exploration of the Earth's Interior. Advances in Science, Technology \& Innovation (IEREK Interdisciplinary Series for Sustainable Development). Springer, Cham.

Bailey, E. H., Stevens, R. E., 1960. Selective staining of potash feldspar and plagioclase on rock slabs and thin sections. Amer. Mineralogist, 45,1020-1025.

Bissell, H. J., Chilingar, G.V., 1967. Classification of sedimentary carbonate rocks. In: Chilingar, G. V., Bissell, H. J. Fairbridge, R. W. (eds.): Carbonate Rocks. Dev. Sed. 9 A, 87-168, 16 PIs., Amsterdam: Elsevier.

Dunham, R. J., 1962. Classification of carbonate rocks according to depositional texture. Mem. American Association Petroleum Geology, 1,108-121.

Folk, R.L., 1959. Practical petrographical classification of limestones. American Association Petroleum Geology Bulletin, 4311,1-38.

Folk, R. L., 1962. Spectral subdivision of limestone types. American Association Petroleum Geology, 1, $62-84$.

Gill, R., 2010. Igneous Rocks and Processes A Practical Guide. Department of Earth Science, Royal Holloway, University of London. Wiley-Black well Publication.

Gillespie, M. R., Styles, M. T., 1999. Classification of igneous rocks. British Geological Survey Research, 2nd edition, 1:52p.

Laniz, R.V., Stevens, R. E., and Norman, M. B., 1964. Staining of plagioclase feldspars and other minerals with F.D. and C red no. 2: U. S. Geological Survey, 501-B.

Le Bas, M. J., Streckeisen, A., 1991. The IUGS systematics of igneous rocks. Journal of the Geological Society of London, 148, 825-833.

Le Maitre, R.W., 2002. Igneous rocks - a classification and glossary of terms. Recommendations of the IUGS subcommission on the Systematics of Igneous Rocks, 2 end Cambridge, Cambridge University Press.

Le Maitre, R.W., Bateman, P., Dudek, A., Keller, J., 1989. A classification of igneous rocks and glossary of term: Recommendations of the International Union of Geological Sciences subcommission on the systematics of igneous rocks. Blackwell Scientific Publications, Oxford.

Leighton, M.W., Pendexter, C., 1962. Carbonate rock types. Mem. American Association Petroleum Geology, 1, 33-61.

Michel-Levy, A., 1889. Structures et classification des rocheseruptives. Librairiepoly technique, Baudry et Cie, Paris.

Streckeisen, A., 1976. To each plutonic rock its proper name. Earth Science Reviews, 12, 1-33. 